\title{
Polymeric Materials for the Development of Dual-Working Gastroretentive Drug Delivery Systems. A Breakthrough Approach
}

\author{
M Violante de Paz* and Roberto Grosso \\ Department of Organic and Pharmaceutical Chemistry, Faculty of Pharmacy, University of Seville, Spain
}

Submission: January 23, 2021; Published: February 04, 2021

*Corresponding author: M Violante de Paz, Department of Organic and Pharmaceutical Chemistry, Faculty of Pharmacy, University of Seville, Spain

\begin{abstract}
Oral route is the most convenient and widely used method of drug administration, representing about $90 \%$ of all therapies used. It displays great advantages, such as being non-invasive, easy to administer (with the consequent high patient compliance) and cost-effective. However, serious drawbacks to conventional oral dosage forms are imposed by the gastrointestinal tract. Large fluctuations in drug bioavailability are found due to the influence of physiological factors such as variations in $\mathrm{pH}$, high enzymatic activity and gastric emptying. This is the reason why frequent drug administrations are required to maintain the therapeutic plasma level of the drug. Gastroretentive Drug Delivery Systems (GRDDS) have emerged as an ideal approach to overcome these drawbacks. They are designed to prolong the gastric residence time (GRT) of the dosage forms in the stomach so that the time between dose administration is lengthened. Although their development has partially overcome the drawbacks associated with conventional dosage form, further work is needed on its shortcomings. The overall objective of this minireview is to highlight the opportunities from the development of dual-working polymeric materials, suitable for their use as GRDDS with improved GRT and capable of overcoming common drawbacks associated with conventional GRDDS. This could be achieved by a combination of properties such as buoyancy, swelling, porosity, and bioadhesion of the synthesized materials.
\end{abstract}

Keywords: Biopolymers; Biodegradability; Delayed Gastric Emptying Devices; Porous Matrices; Microspheres; Dds; Bioavailability; Extended Release; Personalized Healthcare

\section{Introduction}

Spain, with a population of 46.7 million people, is one of the countries with longer life expectancies in the word. The data have been improving substantially in the last two decades reaching the outstanding figures of 80.2 years for males and 85.8 years for women in 2017 (Figure 1). However, the population is aging, and their quality of life is not optimal. Most of our elders suffer from chronic diseases that must be treated continuously for long periods of time with the consequent enormous impact on people's lives. But they do not have the exclusivity of suffering from chronic disorders; a relevant segment of middle-age population is getting into treatment of several diseases such as diabetes, cardiovascular diseases, neurological disorders, and chronic respiratory diseases, just to mention a few examples. This fact draws a notable impact on the Healthy life expectancy (HALE) ${ }^{\mathrm{a}}$ of the population. According to the Institute for Health Metrics and Evaluation (GBD
2017, University of Washington), life expectancy and HALE differ substantially from each other, not only for the Spaniards, but also for all the population from developed countries. As an example, and for comparative reasons, Table 1 records the figures for both parameters, life expectancy and HALE, for population from Western Europe and Spain.

Globally, the market for pharmaceutical spending was expected to surpass $\$ 1.3$ trillion by 2018 [1]. Notably, the main difficulties encountered in achieving effective treatment are related to transport and precise delivery of drugs to specific damaged organs or tissues, because releasing the right amount of drug at the exact location at the suitable rate is not a trivial issue. In this sense, scientific policies should focus on: (a) promoting research on more effective drugs and, to a greater extent, (b) supporting research on more effective drug delivery systems.

${ }^{a}$ number of years that a person at a given age can expect to live in good health, considering mortality and disability. 
Thus, the global outcomes obtained by this research support strategy would conduct to more successful chemotherapeutic effects. For example, some chronic and disabling pathologies, which exert a marked negative impact on human welfare (such as diabetes, Parkinson and peptic ulcer diseases), are treated by the oral administration of active pharmaceutical ingredients (APIs) ${ }^{\mathrm{b}}$. As detailed below, the bioavailability of APIs used in the treatment of these disorders experience fluctuations that may endanger the health of patients. To highlight the relevance of this health problem, Table 2 records the most relevant epidemiological parameters for these three disorders for the inhabitants of Spain and Western Europe.
Table 1: Live expectancy and Healthy Life Expectancy (HALE) for population from Western Europe and Spain (2017, Institute for Health Metrics and Evaluation, University of Washington).

\begin{tabular}{|c|c|c|}
\hline Region & & \\
Parameters & Western Europe & Spain \\
\hline Life Expectancy (years) & 81.91 & 83.06 \\
\hline HALE* (years) $^{*}$ & 70.62 & 72.08 \\
\hline
\end{tabular}

Table 2: Epidemiological parameters of selected diseases: Disability adjusted life years (DALY), ${ }^{c}$ prevalence ${ }^{d}$ and Incidenc ${ }^{e}$ for population from Western Europe and Spain (2017, Institute for Health Metrics and Evaluation, University of Washington).

\begin{tabular}{|c|c|c|c|c|c|c|}
\hline Disease & \multicolumn{2}{|c|}{ Diabetes Mellitus Type 2} & \multicolumn{2}{|c|}{ Parkinson disease } & \multicolumn{2}{|c|}{ Peptic ulcer diseases } \\
\hline $\begin{array}{l}\text { Epidemiological } \\
\text { Parameters }\end{array}$ & Western Europe & Spain & $\begin{array}{c}\text { Western } \\
\text { Europe }\end{array}$ & Spain & $\begin{array}{c}\text { Western } \\
\text { Europe }\end{array}$ & Spain \\
\hline DALYs $^{(a)}$ & 821 & 775 & 166 & 165 & 49 & 30 \\
\hline Prevalence (abs. Data) ${ }^{(\mathrm{b})}$ & $41,619,714$ & $4,080,738$ & $1,012,153$ & 112,788 & 735,903 & 67,386 \\
\hline Incidence (abs. Data) $)^{(\mathrm{c})}$ & $1,862,036$ & 183,931 & 126,105 & 13,771 & 329,833 & 31,113 \\
\hline
\end{tabular}

Source: (a) Disability-adjusted life years (DALYs) per 100,000; (b) Prevalent cases, global numbers (absolute data); (c) Incident cases, global numbers (absolute data)

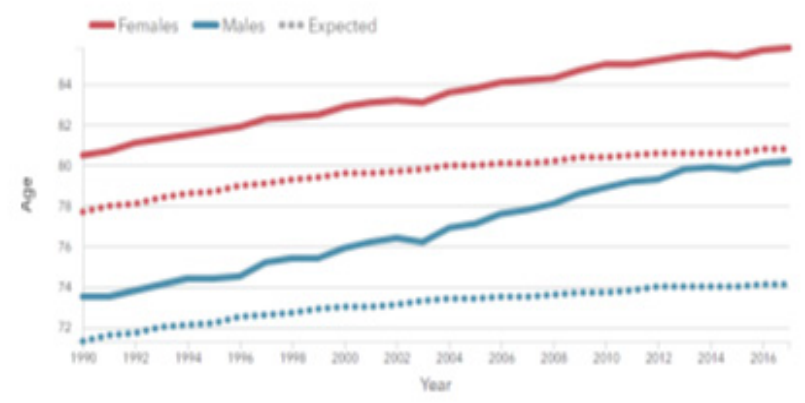

\begin{tabular}{|c|c|c|c|c|}
\hline & \multicolumn{2}{|c|}{ Expected } & \multicolumn{2}{c|}{ Observed } \\
\hline & 1990 & 2017 & 1990 & 2017 \\
\hline Females & 77.7 & 80.8 & 80.5 & 85.8 \\
\hline Males & 71.3 & 74.1 & 73.5 & 80.2 \\
\hline
\end{tabular}

Figure 1: Life expectancy for Spanish women and men from 1990 to 2017 (Institute for Health Metrics and Evaluation, University of Washington).

${ }^{\mathrm{b}}$ Any substance or mixture of substances intended to be used in the manufacture of a drug product and that, when used in the production of a drug, becomes an active ingredient in the drug product. Such substances are intended to furnish pharmacological activity or other direct effect in the diagnosis, cure, mitigation, treatment or prevention of disease or to affect the structure and function of the body.

'The sum of years lost due to premature death (YLLs) and years lived with disability (YLDs). DALYs are also defined as years of healthy life lost.

${ }^{\mathrm{d}}$ The total number of cases of a given disease in a specified population at a designated time. It is differentiated from INCIDENCE, which refers to the number of new cases in the population at a given time.

eThe number of new cases of a given disease during a given period in a specified population. It also is used for the rate at which new events occur in a defined population. It is differentiated from prevalence, which refers to all cases, new or old, in the population at a given time. 
Oral route is the most convenient and widely used method of drug administration, representing about $90 \%$ of all therapies used [2]. It displays great advantages, such as being non-invasive, easy to administer (with the consequent high patient compliance) and cost-effective; they are also easy to store and transport, and the formulations can be modified flexibly. However, serious drawbacks to conventional DDS are imposed by the gastrointestinal tract (GIT). Large fluctuations in drugs' bioavailability are found due to the influence of physiological factors such as variations in $\mathrm{pH}$, high enzymatic activity as well as gastric emptying. In addition, rapid gastrointestinal transit can prevent not only the complete drug release from the dosage form, but also the full drug intake in the absorption zone (most drugs are absorbed in stomach or the upper part of small intestine) with the consequent loss of dose effectiveness. This is the reason why frequent drug administrations are required to maintain the therapeutic plasma level of the drug.

\section{Gastroretentive Drug Delivery Systems (GRDDS)}

Gastroretentive Drug Delivery Systems (GRDDS) have emerged as an ideal approach to overcome the mentioned-above drawbacks. Their main goal is to prolong the gastric residence time (GRT) of the dosage forms in the stomach up to several hours, so that the time between dose administration is lengthened and the drug release proceeds at the desired rate depending on their therapeutic use [3].

\section{Consequently, GRDDS can play a key role in}

a. Prolonging the liberation in stomach of drugs with local activity in the stomach or the upper part of the intestine (Amoxicillin, for eradication of Helicobacter pylori in peptic ulcer diseases, Table 3) [4].

Table 3: Selected oral-administrated drugs susceptible of bioavailability improving by GRDDS.

\begin{tabular}{|c|c|c|c|c|c|}
\hline $\begin{array}{l}\text { Bioavailability chal- } \\
\text { lenge }\end{array}$ & Drug & Therapeutic indication & Chemical Structure & $\begin{array}{l}\text { Bio- } \\
\text { avail- } \\
\text { ability } \\
(\%)\end{array}$ & $\begin{array}{l}\text { Half-life } \\
\text { (h) }\end{array}$ \\
\hline $\begin{array}{l}\text { Active locally in the } \\
\text { stomach }\end{array}$ & $\begin{array}{l}\text { Amoxicillin (in combi- } \\
\text { nation } \\
\text { with Metronidazol) }\end{array}$ & $\begin{array}{l}\text { Peptic ulcer and reflux esophagitis, } \\
\text { eradication of H. pylori }\end{array}$ & & 95 & 1.02 \\
\hline $\begin{array}{l}\text { Soluble in acidic con- } \\
\text { ditions }\end{array}$ & Ranitidine & $\begin{array}{c}\text { *Part of a multidrug regimen for } \\
\text { Helicobacter pylori eradication } \\
\text { *Gastroesophageal reflux disease } \\
\text { (GERD) } \\
\text { *Erosive esophagitis }\end{array}$ & & 50 & $2.5-3$ \\
\hline \multirow{3}{*}{$\begin{array}{c}\text { *Short half life } \\
\text { *Narrow absorption } \\
\text { window }\end{array}$} & $\begin{array}{l}\text { Levodopa (in combina- } \\
\text { tion with carbidopa) }\end{array}$ & Parkinson's disease & & 70 & $0.75-1.50$ \\
\hline & Carbidopa & Parkinson's disease & & 99 & $2 \mathrm{~h}$ \\
\hline & Metformin & Type II diabetes mellitus & ḦH & & $4-8.7$ \\
\hline
\end{tabular}

b. Slowing down the release of drugs soluble at acidic $\mathrm{pH}$ (Ranitidine, H2-receptor antagonists);

c. And prolonging the release of drugs with narrow absorption window, i.e., with low absorption in the lower part of the GIT (Levodopa and Carbidopa, drugs used in the treatment of Parkinson disease), and drugs with low bioavailability such as the antidiabetic Metformin.

\section{Main advantages of current GRDDS}

a. The benefit of low density/floating systems is rooted on the buoyancy of the dosage in the gastrointestinal fluids. Its bulk density must be lower than that found in gastric fluids
(1.004 to $1.010 \mathrm{~g} / \mathrm{mL}$ ). The bulk density is the density value reached after a lag time that depends on the swelling rate of the polymer used in the formulation. This property can be improved by the incorporation of wicking agent or swelling enhancers [59]. Moreover, the use of effervescent combinations, joint to the swelling characteristic, can improve the overall floating behavior of the dosage form [10].

b. Bio(muco)adhesive devices have also been formulated as GRDDS. The dosage forms are designed to be attached to the stomach wall and survive gastrointestinal motility for a longer period. The use of mucoadhesive polymers is necessary [11]. 
c. Swelling and expandable systems (or "plug type systems" due to their pyloric sphincter blocking attribute) have achieved significant success both in vitro and in vivo in order to retain the dosage form in the stomach [11]. Once the polymer meets the gastric fluid, it absorbs water and swells [12]. The selection of a polymer with the appropriate molecular weight and swelling properties is crucial to enable the dosage form to exhibit sustained-release behavior.

\section{Inconveniences to overcome for the optimal final performance of the pharmaceutical formulations}

a. Low density/floating systems require high levels of fluid in the stomach to float and work effectively. They also may stick to each other and provoke obstruction in the GIT, causing gastric irritation. Additionally, formulations consist of a blend of drug and low-density polymers; therefore, the release kinetics of the drug cannot be changed without changing the floating properties of the dosage form and vice versa.

b. Bioadhesive formulations adhere to the stomach mucosa, which is covered by mucus to protect it. The constant turnover of this protection mucus layer, joint to the high stomach hydration, might decrease the bioadhesion of the polymers.

c. Swelling and expandable systems are difficult in maintaining the structural integrity; they may cause bowel obstruction, intestinal adhesion, and gastropathy if they are not constituted by an easily hydrolysable, biodegradable polymers.
Although the development of simple-working GRDDS has partially helped to overcome the drawbacks associated with conventional dosage form, further work is needed on its shortcomings. We propose herein the development of two types of dual-working polymeric materials, suitable for use in GRDDS, which will substantially lengthen the GRT.

New Polymeric Systems towards the Development of GRDDS with Substantial Gains Compared to Known Systems

The preparation of new polymeric materials with optimal properties for the development of efficient dual-working gastroretentive drug delivery systems (GRDDS) is a breakthrough approach. It can improve the bioavailability of selected oral drugs within an authentic biological matrix, which may benefit the 43.4 million people that suffer from diabetes, Parkinson disease and peptic ulcer today in Western Europe (Table 3). This innovative technology will provide reliable dosing of the drugs to the target location and ultimately, the in vitro detection, ensuring proper drug management, enabling personalized healthcare. To achieve it, two routes have been identified to provide disruptive enabling technologies which allows the formation of dual-working GRDDS able to overcome common drawbacks associated to previous systems: (a) The combination of swelling expanding properties with buoyance features is a low-explored concept for improved gastro-retention attributes; (b) the combination of muco-adhesion and floating mechanism.

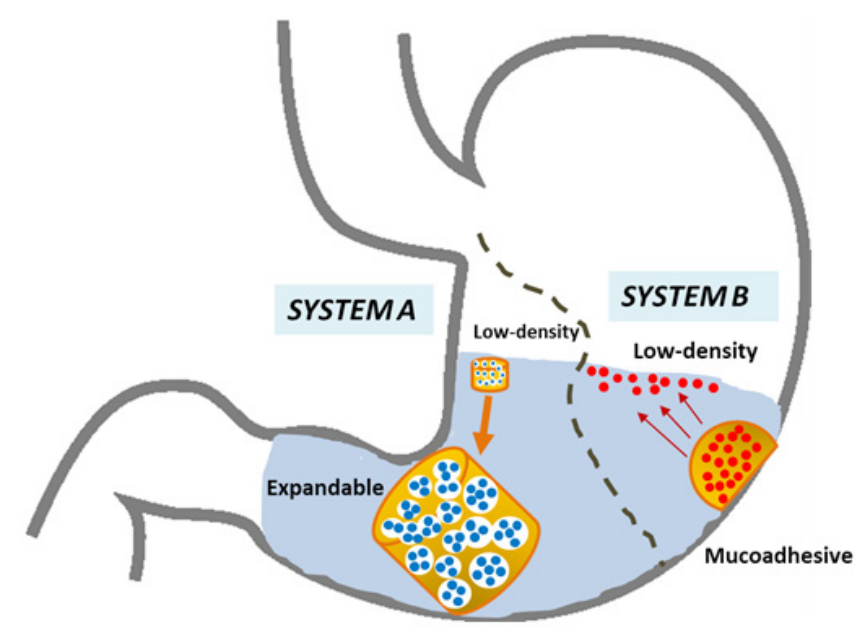

Figure 2: Dual GRDDS to develop in advanced therapies.

Therefore, it could be of interest the development of:

I. Floating expandable materials (System A), able to behave not only as swelling-expandable GRDDS with improved mechanical properties, but also as floating devices.
II. Reversible bioadhesive hydrogels (RBH)/low-density microspheres composites (System B). These devices present the advantages of bioadhesive systems in combination with lowdensity/floating approaches (Figure 2). 
The substantial gains of the target materials over conventional systems are summarized as follows:

\section{Floating expandable materials, over conventional porous systems}

i. A substantial improvement in the final mechanical strength of the system, keeping its efficacy over time.

ii. The porous structure will not depend on $\mathrm{pH}$ and keep swell over time.

iii. Their floating properties will length their GRT.

iv. The highly porous structure will allow the inclusion of large quantities of drugs, if required.

\section{Reversible bioadhesive hydrogels / low-density microspheres composites over conventional floating systems and bioadhesive GRDDS}

i. Thiomers-based hydrogels will enhance the bioadhesive properties of the global composite.

ii. As the gel breaks down and separates from the mucosa, floating microspheres will be delivered, increasing the GRT of the loaded drug.

iii. It is known that small-sized floating dosage forms are less likely to be evacuated from the stomach by the migrating myoelectric complex (MMC), ${ }^{\mathrm{f}}$ thus prolonging the GRT.

iv. Due to their size, risk reduction of obstruction in the GIT will be achieved.

v. As the floating microspheres carry the drug into it, drug release kinetics can be modified by just adjusting the number of microspheres in the final formulation, without affecting to their floating properties.

\section{Preparation of expandable superporous hydrogels (SPHs) with floating properties (System A)}

Interpenetrating polymeric networks (IPNs) are unique "alloys" of cross-linked polymers in which at least one network is synthesized and/or cross-linked in the presence of the other [13]. Depending on the chosen polymer, they enable the formation of SPHs (Figure 3), which can absorb large amounts of water or aqueous fluids (10-1000 times of their original weight or volume) in short periods of time. The formation of (semi) IPN based on hydrophilic natural occurring polymers (sodium alginate, hyaluronic acid and chitosan), or synthetic water-soluble polymers (PVA, and Carbopol $®$ ) could be ani interesting choice. The second polymer will grow into the colloidal medium by means of an orthogonal polymerization/complexation method. The interconnected porous patterns of the new SPHs can encapsulate large doses of hydrophilic drugs, such as Metformin and Ranitidine (Table 3), making them ideal as GRDDS [14]. It is relevant to highlight that these systems must rapidly swell and expand, as well as maintain their integrity in the harsh stomach environment while releasing the pharmaceutical active ingredient [15]. Therefore, the physical entanglement of the polymer chains is a key factor and could help improve the mechanical strength and resiliency of the material. Moreover, floating properties (Table 4 \& Figure4) will be imparted by the free volume generated into the hydrophilic matrices, with the help of comb- like materials [16]. Porosity, swelling properties, floatability and drug loading and release behaviors can be controlled by the appropriate choice of network forming polymers and their rate.

Table 4: Most promising current pharmaceutical technologies for GRDDS.

\begin{tabular}{|c|c|c|}
\hline Type & Requirements & Properties /How they work \\
\hline $\begin{array}{l}\text { Low-density /floating } \\
\text { systems } \\
\text { *Non-effervescent } \\
{ }^{* *} \text { Effervescent }\end{array}$ & $\begin{array}{c}\mathrm{d}<1.004 \mathrm{~g} / \mathrm{mL} \\
{ }^{*} \text { Highly swellable gel-forming polymers } \\
\text { ** The use of a gas-generating agent and/or } \\
\text { volatile liquids }\end{array}$ & $\begin{array}{l}\text { *Bouyant. Free volume into the device } \\
\text { *They remain in the stomach for a prolonged period of time [high } \\
\text { gastric residence time }(\mathrm{GRT})] \text { while the drug is released }\end{array}$ \\
\hline $\begin{array}{c}\text { Bioadhesive } \\
\text { /Mucoadhesive Systems }\end{array}$ & *Mucoadhesive polymer & $\begin{array}{l}\text { *Mucoadhesive properties } \\
\text { - The system must interact with the mucin through electrostatic, } \\
\text { thiols, disulfide, hydrogen, and hydrophobic bonding } \\
\text { - Flexible polymer chains get tangled up with mucin } \\
\text { *Designed to adhere to the gastric epithelial cell surface and prolong } \\
\text { the GRT of drug compounds }\end{array}$ \\
\hline $\begin{array}{l}\text { Expandable Systems = } \\
\text { "plug type system" }\end{array}$ & ${ }^{*}$ Small size for easy oral intake & $\begin{array}{l}\text { *Swelling properties } \\
\text { *Longer GRT through an increase in their volume or shape. Expanded } \\
\text { form prevents passage through the pyloric sphincter }\end{array}$ \\
\hline
\end{tabular}

${ }^{\mathrm{f}}$ The mobility pattern of the stomach is termed as Migrating Myoelectric Complex (MMC). 


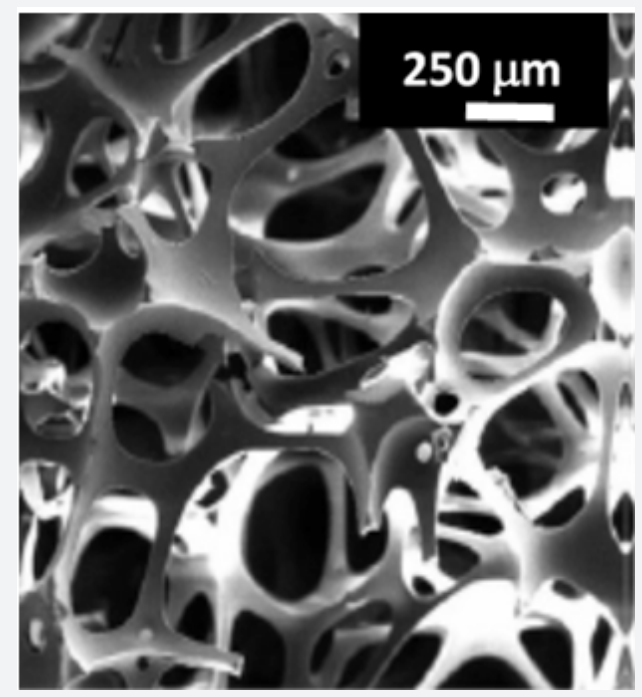

Figure 3: SEM image of SPH micro-structure [17].

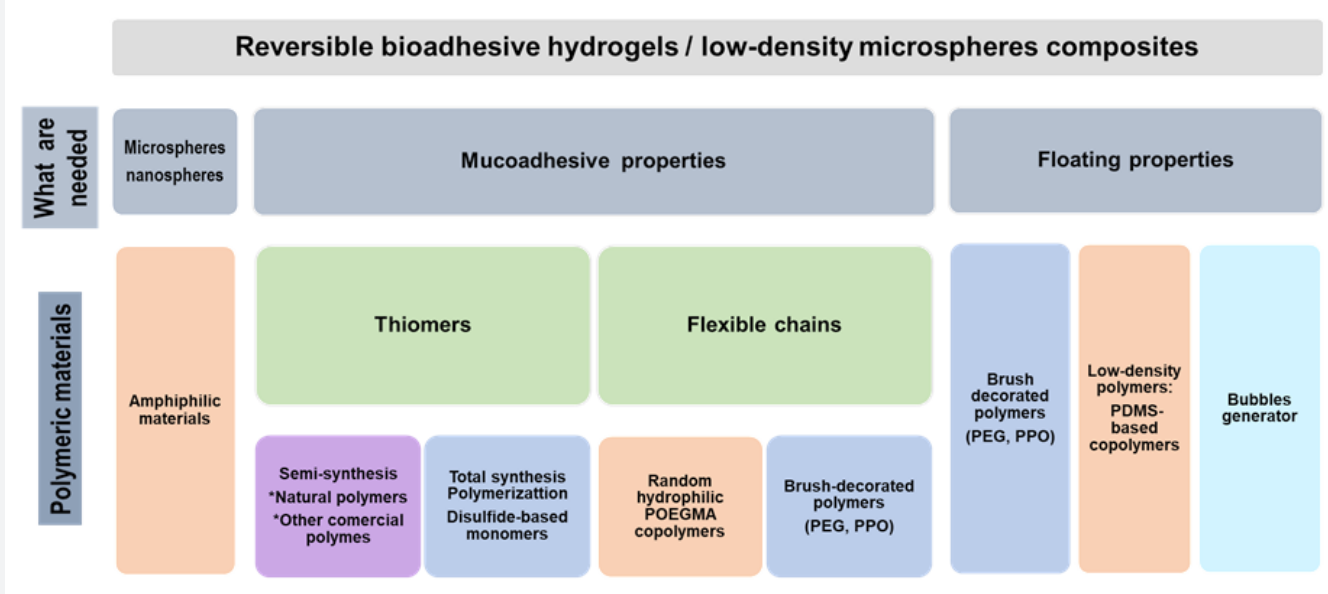

Figure 4: Requirements (properties, devices, polymeric materials and synthetic methods) for the development of System B. PEG: polyethylene glycol; POEGMA: poly(oligoethyleneglycol methacrylate); PPO: polypropylene glycol; PDMS: polydimethylsiloxane.

\section{Development of Reversible Bioadhesive Hydrogels/}

\section{Low-Density (Floating) Nano/Microspheres} Composites (System B)

For the development of reversible bioadhesive hydrogels/lowdensity microspheres composites, properties, materials needed, and polymerization procedures are summarized in Figure 4.

\section{Preparation of floating micro (nano)spheres as lipophilic drug carriers}

Being poly(meth)acrylates biocompatible materials with extensive use in humans,[18,19] the preparation of amphiphilic materials based on (meth)acrylate and (meth)acrylamide derivatives, capable of self-assemble in core-shell structures could be of great interest. To achieve it, extensively tested living polymerization techniques have been already used such as Atom Transfer Radical Polymerizations (ATRP), [20] Oxyanionic Polymerizations [21] and Reversible Addition-Fragmentation Chain Transfer Polymerizations (RAFT) [22,23]. They have demonstrated to be excellent tools for the preparation of amphiphilic block-copolymers. Macromonomers based on PEG, poly(monoglycerol methacrylate) (PGMA), POEGMA, PPO and PDMS will also be used in the polymerization process. They will provide flexibility and low density/floating properties to the final assembled particles (Table 4 \& Figure 4). 


\section{Thiomers. Preparation from natural occurring polysaccharides}

Thiolated polymers or "thiomers", which display thiol bearing side chains, have proved to behave very effectively as mucoadhesive. Their bioadhesive mechanism is based on thiol/ disulfide exchange reactions. Thiomers can form disulphide linkages between them and cysteine-rich subdomains of mucus glycoproteins in the mucus gel layer. This also occurred between the disulphide linkages from polymer backbone and thiol groups in the mentioned glycoproteins [24]. In order to improve the mucoadhesive properties of the materials to use (Table 4), thiolation can be a straightforward method [25]. Although thiolation of natural occurring polymers has already been conducted, [25]. low degree of functionalization were achieved in most cases [26] probably because the sulfhydryl groups are prone to oxidation. The thiolation of natural (chitosan and sodium alginate) and commercial polymers [Carbopol ${ }^{\circledR}$ and poly(vinyl alcohol) PVA] can be conducted by amide-coupling chemistry and the use of thiol-protected molecules such pyridyl disulfide reactants [27]. Based on our experience [28,29] the formation of disulphide containing monomers for polymer total synthesis, can also be addressed.

\section{Flexible chains: Preparation of bioadhesive comb-like polymers}

Entanglement seems to be one of the preferred modes of mucin molecular association. Chain flexibility is critical for interpenetration and entanglement with the mucus gel (Table 4 \& Figure 4) [30]. It has been demonstrated that the incorporation of flexible polymer chains into a hydrogel can promote its mucoadhesion by movement of the polymer chains from hydrogel to mucosa [31]. Hence, the use of flexible comb-type polymers based on PEG, PEGMA, PPO and PDMS will be the first choice. They provide an extra bonus on free volume in hydrogels since physiological temperature is well-above their glass transition temperatures (Tg).

\section{Conclusion}

The benefit of prolonging the release of therapeutic molecules in the stomach whilst reducing the side effects associated with them is evident. The current prescribed, non personalized, traditional oral dosage approach generally involves relatively high doses of the drug in the hope that a portion, although minor, will go to the target tissues. Not only does this overdose lead to a nonsignificant efficiency in combating patients' disease, it also leads to major side effects. Embeddeding the drugs into dual-working GRDDS that posses a double retartant systems for drug delivery, will conduct to a significant improvement in the sustainable drug release over longer time periods. Accurately time delivery of the selected drugs is the only method to reduce drug dosages, mitigate side effects on the other healthy tissues and increased rapidity of the action. In addition, by the designed methods it is possible to maintain the therapeutic drug releases while time intervals between doses is shortened, with the consequent reduction in patient's discomfort. Development of these systems is a key deliverable of the current mini-review.

\section{Acknowledgment}

The authors would like to thank El Ministerio de Ciencia, Innovación y Universidades (MICINN) of Spain (Grant MAT201677345-C3-2-P), and La Junta de Andalucía (Grant P12-FPM-1553) for their financial support.

\section{References}

1. Mahendraratnam N, Dusetzina SB, Farley JF (2017) Journal of Managed Care \& Specialty Pharmacy 23: 355-363.

2. Bhattarai N, Gunn J, Zhang M (2010) Chitosan-based hydrogels for controlled, localized drug delivery. Advanced Drug Delivery Reviews 62(1): 83-99.

3. Lopes CM, Bettencourt C, Rossi A, Buttini F, Barata P (2016) Overview on gastroretentive drug delivery systems for improving drug bioavailability. International journal of pharmaceutics 510(1): 144158.

4. El-Zahaby SA, Kassem AA, El-Kamel AH (2014) Design and evaluation of gastroretentive levofloxacin floating mini-tablets-in-capsule system for eradication of Helicobacter pylori. Saudi Pharmaceutical Journal 22(6): 570- 579.

5. Thapa P, Jeong SH (2018) Effects of Formulation and Process Variables on Gastroretentive Floating Tablets with A High-Dose Soluble Drug and Experimental Design Approach. Pharmaceutics 10(3): 161.

6. Sivaneswari S, Karthikeyan E, Chandana PJ (2017) Novel expandable gastro retentive system by unfolding mechanism of levetiracetam using simple lattice design-Formulation optimization and in vitro evaluation. Bulletin of Faculty of Pharmacy, Cairo University 55(1): 63-72.

7. Malik R, Garg T, Goyal AK, Rath G (2015) Polymeric nanofibers: targeted gastro-retentive drug delivery systems. Journal of Drug Targeting 23(2): 109-124.

8. Tripathi J, Thapa P, Maharjan R, Jeong SH (2019) Current State and Future Perspectives on Gastroretentive Drug Delivery Systems. Pharmaceutics 11(4): 193.

9. Chavanpatil MD, Jain P, Chaudhari S, Shear R, Vavia PR (2006) Novel sustained release, swellable and bioadhesive gastroretentive drug delivery system for ofloxacin. International Journal of Pharmaceutics, 2006, 316(1-2): 86-92.

10. Tadros MI (2010) Controlled-release effervescent floating matrix tablets of ciprofloxacin hydrochloride: Development, optimization and in vitro-in vivo evaluation in healthy human volunteers. European Journal of Pharmaceutics and Biopharmaceutics 74(2): 332-339.

11. Mandal UK, Chatterjee B, Senjoti FG (2016) Gastro-retentive drug delivery systems and their in vivo success: A recent update. Asian Journal of Pharmaceutical Sciences 11(5): 575-584.

12. Arnold J, Hunkeler D (2015) Gastro retention using polymer cocoons. Artificial Cells, Nanomedicine, and Biotechnology 43(1): 26-32.

13. Ahmed EM (2015) Hydrogel: Preparation, characterization, and applications: A review. Journal of Advanced Research 6(2): 105-121. 
14. PerchyonokV,GroblerS,ZhangS(2014)IPNs from Cyclodextrin:Chitosan Antioxidants: Bonding, Bio-Adhesion, Antioxidant Capacity and Drug Release. Journal of Functional Biomaterials 5(3): 183-196.

15. Omidian H, Park K, Rocca JG (2007) Journal of Pharmacy and Pharmacology 59: 317-327.

16. Shakya R, Thapa P, Saha RN (2013) Asian Journal of Pharmaceutical Sciences 8: 191-198.

17. Yin L, Fei L, Cui F, Tang C, Yin C (2007) Superporous hydrogels containing poly(acrylic acid-co-acrylamide)/O-carboxymethyl chitosan interpenetrating polymer networks. Biomaterials 28(6): 1258-1266

18. Iglesias N, Galbis E, Díaz MJ, Paz MV, Galbis JA (2018) Loading studies of the anticancer drug camptothecin into dual stimulisensitive nanoparticles. Stability scrutiny. International Journal of Pharmaceutics 550(1-2): 429-438.

19. Otsuka H, Nagasaki Y, Kataoka K (2012) Advanced Drug Delivery Reviews 64: 246-255.

20. Bütün V, Wang XS, Banez MV, Robinson KL, Billingham NC, et al. (2020) Macromolecules 33(1): 1-3

21. Banez MV, Robinson KL, Vamvakaki M, Lascelles SF, Armes SP (2000) Synthesis of novel cationic polymeric surfactants. Polymer 41(24): 8501-8511.

22. Moad G, Rizzardo E, Thang SH (2009) Living Radical Polymerization by the RAFT Process - A Second Update. Australian Journal of Chemistry 62(11): 1402-1472.
23. Martínez MB, Galbis E, Carmona AT, Paz MV, Robina I (2019) European Polymer Journal 119: 213-221.

24. Bernkop SA (2005) Thiomers: a new generation of mucoadhesive polymers. Advanced drug delivery reviews 57(11): 1569-1582.

25. Grabovac V, Guggi D, Bernkop S (2005) Comparison of the mucoadhesive properties of various polymers. Advanced Drug Delivery Reviews 57(11): 1713-1723.

26. Cook MT, Khutoryanskiy VV (2015) Mucoadhesion and mucosamimetic materials--A mini-review. International Journal of Pharmaceutics 495(2): 991-998.

27. Boyer C, Liu J, Wong L, Tippett M, Bulmus V, et al. (2008) Stability and utility of pyridyl disulfide functionality in RAFT and conventional radical polymerizations. Polymer Chemistry 46(21): 7207-7224.

28. Romero AL, Benito E, Martínez A, García AG, Galbis JA (2018) Polymer Degradation and Stability 153: 262-271.

29. Romero AE, Benito MG, García M, Galbis JA (2017) European Polymer Journal 94: 259-269.

30. Ludwig A (2005) The use of mucoadhesive polymers in ocular drug delivery. Advanced Drug Delivery Reviews 57(11): 1595-1639.

31. Peppas NA, Sahlin JJ (1996) Hydrogels as mucoadhesive and bioadhesive materials: a review. Biomaterials 17(16): 1553-1561.

\section{Your next submission with Juniper Publishers will reach you the below assets}

- Quality Editorial service

- Swift Peer Review

- Reprints availability

- E-prints Service

- Manuscript Podcast for convenient understanding

- Global attainment for your research

- Manuscript accessibility in different formats ( Pdf, E-pub, Full Text, Audio)

- Unceasing customer service

Track the below URL for one-step submission https://juniperpublishers.com/online-submission.php 